\title{
Tobacco Control Strategies Enrich the National Strategic Plan on Prevention and Control of Cancer in Sri Lanka
}

\author{
Samadhi Wishwanath Rajapaksa ${ }^{1 *}$, Janaki Vidanapathirana ${ }^{2}$, Sashiprabha \\ Nawaratne $^{2}$, Malawige Amila Suranga ${ }^{2}$
}

\begin{abstract}
The National Cancer Control Programme Sri Lanka is the main government organization and focal point for coordinating the national response to prevention and control of cancer activities. Present National strategic plan on Cancer Prevention and Control (2020-2024) was developed by multi-sectoral expert groups. The present strategy derives its mandate from the overarching National policy documents including the NATA Act. Strategic objectives one and two of the National Strategic Plan identified the tobacco control measures. Several databases were searched to find out the relevant literature relevant to tobacco control strategies in Sri Lanka and the rest was collected from the university libraries, experts, and key persons in the field from the legal, and health sectors. It was identified more than 200 documents relevant to tobacco control. Strong legal legislations are available for measures to reduce the demand for tobacco products. Those are Protection from exposure to tobacco smoke, regulation of the contents of tobacco products, regulation of tobacco product disclosures, packaging and labeling of tobacco products, tobacco advertising, promotion and sponsorship, licit trade in tobacco products, sales to under 21, Provision of support for economically viable alternative activities. These legislations are covering by the NATA act. New formula for tobacco taxation was submitted to the Ministry of Health. Conclusion: Strong tobacco controlling laws and legislations are available in Sri Lanka that supports achieving one and two of the strategic objectives of the National strategic plan on cancer prevention and control in Sri Lanka. Policies are needed to regularize the increased tax rates to adjust for inflation and Gross Domestic Product. WHO has categorized Sri Lanka as one of the countries which can likely achieve a decrease in tobacco smoking prevalence (30\%) by 2025 .
\end{abstract}

Keywords: Cancer National Strategic plan- Sri Lanka-Tobacco control, NATA- Sri Lanka- Cancer Control -Sri Lanka

Asian Pac J Cancer Prev, 22, Progress of Tobacco Control in the South-East Asia Region Suppl, 45-50

\section{Introduction}

The National Cancer Control Programme Sri Lanka is the main government organization and focal point for coordinating the national response to prevention and control of cancer activities in Sri Lanka. Present National Strategic Plan on Prevention and Control of Cancer in Sri Lanka (2020-2024) was developed by multi-sectoral expert groups from both government and non-governmental organizations including community participation with a vision to keep the country with a low incidence of preventable cancers and high survival rates with good quality of life and minimal disabilities $\&$ suffering from effects of cancers (NCCP 2020). The present strategy derives its mandate from the overarching National Health Policy and aligned to the National Health Strategic Master Plan 2016-2025, Global Action Plan for Prevention and Control of NCDs and National Multisectoral Action Plan for the Prevention and Control of Non Communicable Diseases in Sri Lanka (2016-2020) including the National Authority on Tobacco and Alcohol Act and WHO Framework Convention on Tobacco (WHO FCTC) and other relevant policy documents. All these documents have identified tobacco control strategies and those are identified in the current National Strategic Plan on Prevention and Control of Cancer in Sri Lanka (2020-2024). The objective one and two of the National Strategic Plan of Cancer Prevention and Control address the activities relevant to the tobacco control measures.

Implementation of National strategic plan on Cancer Prevention and Control including the tobacco related strategies has a shared responsibility of several stakeholders including government in particular health services including the National Authority on Alcohol and Tobacco, nongovernmental organizations, civil society organizations, community based organizations, academia, professional organizations, communities, patient groups and their families.

National Cancer Registry, Sri Lanka revealed that there were a total of 31874 newly diagnosed cancers in 
year 2019 (NCCP 2021). Globocan estimated that around 75000 cancer patients in Sri Lanka at a given point of time in year 2020. National Cancer Registry, Sri Lanka, further stated that top cancer among male were Lip, tongue and mouth (15\%), which is the highest, followed by Lung, bronchus and lung cancer $(8 \%)$, Colorectal (9\%), Oesophagus (9\%), Prostate (4\%), Pharynx (4\%) and female top cancers were breast $(27 \%)$ followed by Thyroid (13\%), Colorectal (7\%), Cervix (7\%), Uterus (6\%), Ovary (6\%), Oesophagus (5\%).

Tobacco is a risk factor for most of these top ten cancers among both males and females in Sri Lanka. When considering aetiology of cancers, exposure to risk factors has a major contribution for genetic damage while hereditary factors cause minor contribution (Ferguson 2015, Roukos 2009). Tobacco is one of the commonest risk factors for cancer and categorized as a type one carcinogen. Tobacco causes 15 types of cancers (oral, lung, pharynx, Larynx, cervical, colorectal, prostate, bladder, kidney oesophagus, cervix, breast, ovary, etc..) in the human body. These cancers can be prevented and reduce the incidence by preventing exposures to tobacco, some of these cancers have good survival if detected early. Around $30 \%$ of global cancer deaths are due to tobacco use and about $80 \%$ of lung cancers, as well as about $80 \%$ of all lung cancer deaths, are due to smoking. In Sri Lanka, tobacco kills $10 \%$ of all deaths in the country. In 2016, cancers reported 3 rd the highest mortality (23 per 100,000 population) contributing $11.5 \%$ of hospital deaths in Sri Lanka (Ministry of Health 2016).

The STEPS survey, 2015 has highlighted the magnitude of the tobacco problem when it records that nearly $45.7 \%$ males of 15-69 years consume tobacco in either smoke or smokeless (Ministry of Health, Nutrition and Indigenous Medicine and World Health Organization (2015)). Among males 29.4\% were current tobacco smokers and $26.4 \%$ were current smokeless tobacco users. In women smokeless tobacco use (5.3\%) was more prevalent than tobacco smoking $(0.1 \%)$. The Global School Based Health Surveillance System survey (GSBHSS) done among 13-17 year old students recorded the prevalence of current use of any form of tobacco to be $9.2 \%$ with $3.5 \%$ being current tobacco smokers and $2.3 \%$ were smokeless tobacco users in Sri Lanka (WHO-SEA 2016).

Exposure to secondhand smoke by tobacco products causes disease and premature deaths in non-smokers. The second-hand smokers are at increased risk for lung cancer. GSBHSS reports that a significant amount $(42.3 \%)$ of students was exposed to secondhand smoke as either a parent or guardians were smokers. Most of these products are imported from neighboring countries. The best approach to preventing tobacco related cancer is preventing the uptake of tobacco in any form. In 2015, the direct and indirect costs of tobacco related diseases was estimated to be SLR 89.37 billion (USD 662 million) and the cost related to cancers was SLR 16.3 billion (USD 121.1). Oral cancer which is associated with tobacco chewing habits is the commonest cancer among Sri Lankan males and was the major contributor to cancer costs of tobacco (Amarasinghe et al., 2017).

Sri Lanka is committed to achieve the globally set targets by 2025 and tobacco related targets are: $25 \%$ reduction in premature mortality from cancer and a $30 \%$ relative reduction in prevalence of current tobacco use in persons aged over 15 years. To achieve these targets tobacco control strategies have been included under the strategic objective one: high level leadership, advocacy and governance to accelerate the national response for prevention and control of cancer and strategic objective two primordial \& primary prevention of cancers by addressing risk factors and determinants throughout the life-cycle of the National Strategic plan. Under these strategic objectives it has been identified main activities and detailed activities including tobacco control activities. The implementation of these activities have been assigned to multisectoral institutions including advocacy, implementations of laws, developing guidelines, capacity building. Knowledge update and knowledge sharing, monitoring the activities related to the implementation of laws. Therefore, it is important to identify the tobacco control strategies which enrich the National strategic plan on cancer prevention and control in Sri Lanka. Then it will facilitates the tobacco control strategies and monitoring and evaluation of the National strategic plan yearly and midterm review of cancer spectrum during year 2022 .

Objective: Aim of this study is to describe how the Sri Lankan tobacco strategies help the National Strategic Plan on Prevention and Control of Cancer in Sri Lanka (2020-2024).

\section{Materials and Methods}

Several databases were searched to find out the relevant literature (eg: Google scholar) and the rest was collected from the university libraries, experts and key persons in the field from legal, and health sectors. Data database of the NATA library was searched to final the relevant legal documents. it was identified more than 200 documents relevant to tobacco control documents and categories into different subcategories and different agencies. Later all these documents categorised under main subheading: governance on tobacco control, laws related to tobacco control for demand reduction, Capacity building and provision of support for economically viable alternative activities.

\section{Results}

This review revealed that there are number of supportive policies and strategies available in Sri Lanka which oversee and support the preventive strategies of the National Strategic Plan on Prevention and Control of Cancer in Sri Lanka which ensure a conducive environment to control tobacco use.

\section{Governance on tobacco control}

Sri Lanka has many governing structures to control tobacco products and it applies to reduce exposure, reduce demand, reduce availability and implementations of laws and legislations. Sri Lankan government authority for tobacco control is the National Authority on Tobacco and Alcohol (NATA). In 2003, Sri Lanka ratified the WHO 
Framework Convention on Tobacco Control (FCTC) as the first country in Asia and the fourth in the world. In 2006, the government of Sri Lanka introduced tobacco controlling law and regulations in Sri Lanka under the National Authority on Tobacco and Alcohol Act, No. 27 of 2006 which was amended in 2015 as the National Authority on Tobacco and Alcohol Act (Amended) No.3 of 2015. The NATA Act regulates all aspects of tobacco control in the country. World Health organization introduced "Best Buys" strategies and it support the National Strategic Plan on Prevention and Control of Cancer in Sri Lanka (World Health Organization, 2017).

The National Strategic Plan on Cancer Prevention and Control is supported by the National Advisory Committee on Cancer Prevention and Control and National Non-Communicable Disease Council, consisting of many stakeholders including representation of NATA, where policy decisions are taken on tobacco prevention and control. This is further strengthened by the Technical Advisory Committee on Prevention and Early Detection of cancer which is under the National Advisory Committee on Cancer Prevention and Control. Capacity building and implementations of laws regarding tobacco control at provincial and district level further strengthen tobacco control strategies at regional level. Authorized officers for the implementation of legislations are public health Inspectors who are attached to the medical officer of Health. In addition to that custom officers and excise officers are working as authorized officers for implementation of legislation.

\section{Measures to reduce demand for tobacco products}

There are many strategies being implemented to reduce the demand for tobacco products. It includes price and tax measures of tobacco, protection from exposure to tobacco smoke, regulation of the contents of tobacco products, regulation of tobacco product disclosures, packaging and labelling of tobacco products, community empowerment, preventing licit trade in tobacco products, and prohibiting sales to under 21 years.

\section{Packaging and labelling of tobacco products}

NATA act covers the Packaging and labelling of tobacco products and it revealed that Sri Lanka implemented the pictorial warning of $80 \%$ in the total area of a packet, package or a carton in the both sides of the cigarette packets through a parliament act in 2015 . This was further advised to include health messages and should be changed every six months. This helps to provide accurate information about the risk associated with tobacco use and help to reduce tobacco use by stimulating tobacco users.

\section{Price and tax measures of Tobacco Tax Act}

Sri Lanka imposes a tax on cigarettes, cigars, beedies, cigarette substitutes and pipe tobacco carried by the legislative support of the Tobacco Tax Act, No 8 of 1999, which was amended in 2004. According to the act, the government can change excise tax several times per year. This tax system fluctuating in many times and it not according to a formula based one. At the moment, a five- tier specific excise tax system is used for cigarettes. This tax system is based on the length of the cigarette, where the cigarettes with the highest length have the highest taxation. The Nation-building tax (NBT) of $2 \%$ of the wholesale price is also levied on cigarettes. The value-added tax (VAT) rate was $15 \%$ in 2002-2008. The largest changes in cigarette taxation in Sri Lanka took place at the end of 2016. In October 2016, excise rates were increased by 26$28 \%$ for two higher tiers, by $37-40 \%$ for two middle ties, and by $67 \%$ for the lowest tier. From November 1, 2016, the VAT rate was increased to 15 percent, and cigarettes were again made liable for VAT and NBT. The main aim of this taxation to make tobacco products less affordable to the community and it support the cancer prevention and control too. However, NATA has been submitted a new tax policy to the Finance Ministry according to a formula adjusting for inflation and Gross Domestic Products.

\section{Protection from exposure to tobacco smoke}

There are a number of protection laws and policies are available in Sri Lanka. NATA act further regulate to exposure to secondhand smoking by prohibiting smoking in many enclosed public places, such as government departments, office premises, court houses, libraries, schools, universities, educational institutions, health care facilities, and public transport. This reduce the direct exposure and indirect secondhand exposure. However, it does not cover the open public places.

\section{Regulation of the contents of tobacco products}

Sri Lanka further prohibits misleading packaging and labeling, which includes phrases like "light" and "low." when describing tar and nicotine contents in tobacco products during manufacturing, importing, or selling smokeless tobacco products, This further forbidden tobacco-containing e-cigarettes, and flavored, colored, or sweetened cigarettes.

\section{Regulation of tobacco product disclosures}

The prohibition on the installation of vending machines for dispensing tobacco products, prohibition of tobacco advertisements and sponsorships have been included in the NATA act. Including the free distribution of tobacco products, use of trademarks of tobacco products on any article which is not a tobacco product further control of tobacco control.

\section{Tobacco advertising, promotion and sponsorship}

Tobacco advertisement as, among other things, any moving picture and/or audible message that promotes the purchase or use of a tobacco product are prohibited under the NATA act and prohibits such advertisement in television and film. The law further prohibits tobacco industry sponsorship. Instructions to TV channels additionally prohibit smoking scenes in TV programs produced after NATA became effective in 2006. The law is interpreted as banning paid placement of tobacco products in TV, film or other media.

\section{licit trade in tobacco products}

Although elicit tobacco products are prohibited in Asian Pacific Journal of Cancer Prevention, Vol 22 
exercise regulations and custom regulation, it is moving without in certain instances.

\section{Sales to under 21 years}

Selling tobacco products to minors under 21 years old, have been prohibited by the NATA act which helps to prevent early exposure of young people to tobacco products. On a separate note, a circular issued by the Ministry of Education (Circular No. 20/2020) bans the use, sale, and promotion of tobacco and related products in educational facilities under the purview of the Ministry of Education (Ministry of Education, 2020). Similarly, the University Grants Commission issued a circular (Circular no. 08/2019) prohibiting the use of betel, tobacco and areca nut related products in the premises of state institutions under the university system to prevent exposure and availability of tobacco to facilitate implementation of the NATA act (University Grants Commission, 2019).

\section{Selling of single sticks}

NATA has proposed to pass a new amendment prohibiting the sales of single stick cigarettes aiming to reduce affordability of cigarettes.

\section{Community empowerment}

Different government organizations, Communitybased organizations, non-governmental organizations, and professional bodies also play an important role in tobacco control in Sri Lanka. These multi sectoral partnerships are supportive to advocate policymakers and politicians in favoring public health decisions over industry-friendly alternatives in tobacco control. In addition, numerous agencies carry out activities to facilitate demand reduction of tobacco by community empowerment. Some of the agencies are closely work with the National Cancer Control Programme and some are represent the National advisory committee and technical advisory committees relevant to cancer spectrum.

Toll free telephone quit line / help line which is operated by NATA help to community support for tobacco prevention advises. In addition, empowerment and the cessation and counselling support are provided by island wide healthy lifestyle clinics which is attached to the primary health care institutions and mental well-being clinics under the Ministry of Health.

In addition to that significant number of "tobacco free villages" have established in different places of the country under guidance of NATA with community ownership.

\section{Provision of support for economically viable alternative activities}

One of the most common misconceptions is that tobacco regulations ruin small-scale tobacco growers' livelihoods. In truth, the tobacco industry's immediate benefits vastly outweigh the severe social and environmental consequences. Also, front line illicit player groups are spreading misleading information. However, there is a supportive policy environment for farmers to transition to other crops, which enhances food security while also contributing to export earnings and farm income. For example, tobacco farming has been de-emphasized in the "Sustainable Sri Lanka 2030 Vision and Strategic Path" economic development strategy in order to make room for agribusiness partnerships for high-value food crops (Presidential Expert Committee, 2019). The "National Export Strategy 2018-2022," which lays out a plan for achieving Sri Lanka's export vision, has given special emphasis to food and beverage crops that are better alternatives to tobacco plantation (Ministry of Development Strategies and International Trade Sri Lanka, 2018). Furthermore, the current national agriculture policy has not identified prevention of tobacco farming as a strategic priority (Ministry of Agriculture Development and Agrarian Services Sri Lanka, 2017).

\section{Discussion}

Strong tobacco control laws and legislations are available in Sri Lanka and implementation is carried out based on the NATA act with the help of multi sectoral partnership. NATA act covers all the areas of tobacco control except few areas. Many Sri Lankan national and local research demonstrates that current tobacco prevalence has decreased. This could be due to the strong legal framework of tobacco control strategies implemented by NATA with multi-sectoral partnership. Although the existing legal framework facilitates enrichment of the National Strategic plan on Cancer prevention and control, challenges do exist in some areas due to shortcomings of monitoring of implementation of these legislations.

Although Sri Lanka implements taxation policy on tobacco products, " it was not utilized to its fullest potential. It was observed that the taxes tend to fluctuate and is not maintained in a fixed way due to inflation. From 2005-2015, the excise tax rates for most tiers of cigarettes were increased by about $300 \%$; however, the inflation rate for those eleven years combined was $260 \%$. Therefore, the taxation has had little effect on the affordability of cigarettes over the years. When comparing cigarette affordability in Sri Lanka, in 2009, 2013 and 2015, cigarettes became slightly less affordable, compared to 2010, 2011 and 2014, where it became more affordable. From 2009-2015, combined cigarette affordability almost did not change. Only in 2016, a significant reduction in cigarette affordability was noted in Sri Lanka. According to the WHO Global Tobacco Report 2017, Sri Lanka had the highest retail price for cigarettes among the countries of the WHO South-East Asia Region (SEARO) in 2016. This was partly caused by the highest net-of-tax cigarette price, indicating that taxes can be raised by reducing the net of tax, keeping everything else constant. On the other hand, some of the shortcomings of the tobacco taxation in Sri Lanka is due to having different excise tax rates for different kinds of cigarettes which has resulted in people shifting to cheaper products such as beedi where tax rates are low. Moreover, the lack of effective policies to tackle the problem of smuggled / illicit tobacco in the country were also noted. However, attempts to arrive at 
estimates on illicit cigarettes / smuggling and its effects were hampered by data limitations. On the flip side, the National Authority on Tobacco \& Alcohol has developed a new tobacco taxation formula by considering the inflation rates and Gross Domestic Product of Sri Lanka and is yet to be implemented by the Finance Ministry. Once the new taxation policy is approved and implemented, it will regularize tobacco taxation and achieve its fullest potential.

The strategy of making cigarettes less affordable to the community has been hampered by the sale of single sticks in Sri Lanka. With the sales of single cigarettes, the purpose of pictorial health warnings in the cigarette packs as well as increasing the taxation in order to reduce the affordability had become challenged.

The current demand reduction measures for tobacco and tobacco related products in Sri Lanka has few grey areas which needs to be addressed to meet the FTCT goals. The current law bans smoking in enclosed public places which should be expanded to all public places to protect people from tobacco smoke. This issue in the key term has hampered its application and implementation. Advertising on tobacco is banned on most major forms of media but product displays at point of sale and cross border advertising have not been banned including internet sales. Therefore, enactment and enforcement of a comprehensive ban on all forms of tobacco advertising, promotion and sponsorship is needed to be strengthened. In addition, Sri Lanka has implemented policies banning sales of smokeless tobacco, and its equally important to develop policies banning its production.

Even Though legislation is in place, it has been a real challenge of prohibition and control of smokeless tobacco in Sri Lanka. Chewing tobacco has been connected to the culture and traditions of the country and has become difficult to remove this practice away from communities. Even though there are several legislations laid against chewing tobacco in the food act, the practicality of implementing them has been a real challenge.

Smoke free environment encourages smokers to reduce smoking or attempt to quit and remain tobacco free in the long term, to achieve that Sri Lanka has established tobacco free villages and is in the process of establishing more. Also, it was noted that, the tobacco industry interference index for Sri Lanka was 53\%. Therefore, we have to identify new strategies to counteract the industry interference in tobacco control.

On a positive note, Sri Lanka has the highest specific legal minimum age group for accessing tobacco products which is 21 years. However, a large percentage of youth groups have seen pro-cigarettes advertisements in print and entertainment media during the last 30 days. Another positive achievement to tobacco control was banning of E-cigarettes completely. Moreover, Sri Lanka is committed to shift all tobacco farmers to alternative crops which will also bring positive benefits to the exports sector as well. It was observed that tobacco legislation laboratories are not established Sri Lanka.

It was observed that implementation and monitoring of laws have been a challenge in certain stages: especially tobacco promotion through smoking scenes in films and television series. Even though there is a sensor board, it has failed to take action to remove such scenes in some instances. However, this can be overcome by having a separate regulatory monitoring mechanism under the NATA. Further, monitoring and evaluation of violations to article 5.3 of FTCT can be integrated to different institutional policies. The NATA act has identified authorised officers to implement the provisions of the act. However, due to insufficient human resources or increased working load, violations of the legislation are poorly monitored in some instance. Therefore, developing a close monitoring programme for authorized officers is a timely need. Similarly, community empowerment strategies need to be identified for monitoring and evaluation for tobacco control activities.

To improve on the existing legislations and to identify loopholes, NATA should conduct an external evaluation of the national tobacco control programme, that will further strengthen the tobacco control strategies in the country. Finally, the continuation and consolidation of tobacco control activities in Sri Lanka necessitates a strong and long-term political commitment, technical expertise in evidence-based strategies, and continued multi-sector involvement, with the health needs of the country's citizens taking precedence over economic interests. This will invariably enrich the National strategic plan on prevention and control of cancers in Sri Lanka.

In conclusion, strong tobacco controlling laws, regulations and legislations are available in Sri Lanka that support achieving the current National strategic plan on cancer prevention and control. Implementation of laws and legislations should be improved in certain areas.

Strong good Governing system is available in Sri Lanka to support tobacco control. These strong legal legislations are available under the NATA act and it has included to reduce demand for tobacco products. under the. Those are protection from exposure to tobacco smoke, regulation of the contents of tobacco products, regulation of tobacco product disclosures, packaging and labelling of tobacco products, tobacco advertising, promotion and sponsorship, licit trade in tobacco products, sales to under 21, Provision of support for economically viable alternative activities. These legislations are covering NATA act. Different multi-sectoral agencies are implementing community empowerment programmers. Price and tax measures of tobacco tax is fluctuating and new proposal has been submitted to the Finance Ministry adjusting for inflation and Gross Domestic Products. Banning of selling a single stick, advertising and promotion at point of selling haven not placed

Need for effective policies to counteract tobacco smuggling and other kinds of illicit tobacco sales should be set in place. Sri Lanka has not banned the sale of single sticks of cigarettes, advertising at point of sale and internet advertising of tobacco products.

These available strong legislations are help to achieve strategic objective one and two of the National Strategic Plan on Cancer Prevention and Control in Sri Lanka (2020-2024) relevant to tobacco control.

WHO has identified and categorized, Sri Lanka as one of the countries which can likely to achieve decrease in

Asian Pacific Journal of Cancer Prevention, Vol 22 
tobacco smoking prevalence (30\%) by 2025 .

\section{Recommendation}

It is recommended to further reinforce laws relevant for tobacco control and implement the new tobacco tax policy by advocating policy makers. New regulations should be established for prohibiting of point of sale advertising, internet advertising and sale of single sticks of cigarettes. The strengthening the implementation of laws and legislations relevant to tobacco control should have close monitoring system and conducting an external review. National level multi sectoral partnership should be further strengthened for tobacco control activities and further strengthening of partnership between NATA and National Cancer Control Programme is needed to enrich the National Strategic Plan.

\section{Author Contribution Statement}

None.

\section{Acknowledgements}

The publishing cost was provided by WHO office in South-East Asia.

\section{References}

AmarasingheH, Ranaweera S, Ranasinghe T, et al (2017). Economic cost of tobacco-related cancers in Sri Lanka. BMJ Publishing Group Ltd. Available from: https://www. researchgate.net/publication/320680442_Economic_cost of_tobacco-related_cancers_in_Sri_Lanka.

Ferguson LR, Chen $\bar{H}$, Collins AR, et al (2015) Genomic instability in human cancer: Molecular insights and opportunities for therapeutic attack and prevention through diet and nutrition. Semin Cancer Biol, 35, 5-24.

International Agency for Research on Cancer and World Health Organization. Global cancer Observatory, Cancer Today -2020 [Internet]. France: IARC; 2020. Available from: https://gco.iarc.fr/today/home.

Ministry of Agriculture Development and Agrarian Services Sri Lanka. Sri Lanka National Agriculture Policy [Internet]. 2017, p. 1-10. Available from: http://www.agrimin.gov.lk/ web/images/docs/1252389643AgPolicy4.pdf.

Ministry of Education Sri Lanka. Establishment Circular 20/2020: Making the Premises of Educational Institutes the Zones free from using and promoting Tobacco based Products, Alcohol and other Related Substances [Internet]. Battaramulla: Ministry of Education; 2020. p. 2-4. Available from: https://www.tobaccocontrollaws.org/files/live/Sri Lanka/Sri Lanka - MOE Circular No. 20_2020.pdf.

Ministry of Health, Nutrition and Indigenous Medicine and World Health Organization (2015). Non communicable disease risk factor survey, Sri Lanka, 2015. [Internet]. Available from: https://www.who.int/ncds/surveillance/ steps/STEPS-report-2015-Sri-Lanka.pdf.

Ministry of Health, Nutrition \& Indigenous Medicine (2016). Annual Health Bulletin. Colombo. Ministry of Health, Nutrition \& Indigenous Medicine, Colombo, Sri Lanka.

Ministry of Development Strategies and International Trade Sri Lanka. National Export Strategy of Sri Lanka [Internet]. Colombo; 2018. Available from: http://www. srilankabusiness.com/pdf/nes/sri-lanka-nes-4-3-web.pdf.
National Cancer Control Programme Sri Lanka (NCCP 2020) National Strategic Plan on Cancer Prevention and Control in Sri Lanka ( 2020-2024) [Internet]. Colombo, Sri Lanka: National Cancer Control Programme Sri Lanka;2021. Available from https://www.nccp.health.gov.lk/storage/post/ pdfs/National\%20Strategic\%20Plan(24-11-20).pdf.

National Cancer Control Programme Sri Lanka (NCCP 2021). National Cancer Registry Sri Lanka,Cancer Incidence Data. 2021 [Internet]. Colombo, Sri Lanka: National Cancer Control Programme Sri Lanka;2021. Available from: https:// www.nccp.health.gov.lk/en/incedencedata.

Parliament of the Democratic Socialist Republic of Sri Lanka. National Authority on Tobacco and Alcohol (Amendment) Act, No. 3 of 2015 [Internet]. Sri Lanka; 2015 p. 0-25. Available from: https://www.tobaccocontrollaws.org/files/ live/Sri Lanka/Sri Lanka - NATA Amdt. No. 3 of 2015.pdf

Roukos DH. Genome-wide association studies(2009) how predictable is a person's cancer risk?. Exp Rev Anticancer Ther, 9, 389-92.

University Grants Commission Sri Lanka. Establishment Circular 08/2019: Prohibition of using and Selling of Betel, Tobacco and Areca Nut Related Products in the Premises of State Institutions [Internet]. Colombo: University Grants Commission; 2019. Available from: https://www.ugc.ac.lk/ index.php?option=com. coandrecanutrelatedproductsinthe premisesofstateinstitutions \&catid $=171 \% 3$ A2019\&Itemid $=47 \&$ lang $=$ en.

World Health Organization- Regional Office for South-East Asia (2016). Sri Lanka 2015 country report: global youth tobacco survey, World Health Organization.

World Health Organization.(2017).. The updated Appendix 3 of the WHO Global NCD Action Plan 2013-2020 [Internet]. Geneva: World Health Organization; 2017.Available from http://apps.who.int/gb/ebwha/pdf_files/WHA70/A70_R11en.pdf. presidential Expert Committee. Sustainable Sri Lanka 2030 Vision and Strategic Path [Internet]. Colombo; 2019. Available from: http://www.presidentsoffice.gov. lk/wp-content/uploads/2019/05/Final-v2.4-Typeset-MMv12F-Cov3.pdf.

World Health Organization (2017). The updated Appendix 3 of the WHO Global NCD Action Plan 2013-2020 [Internet]. Geneva: World Health Organization; 2017.Available from http://apps.who.int/gb/ebwha/pdf_files/WHA70/A70_R11en.pdf. Presidential Expert Committee. Sustainable Sri Lanka 2030 Vision and Strategic Path [Internet]. Colombo; 2019. Available from: http://www.presidentsoffice.gov. lk/wp-content/uploads/2019/05/Final-v2.4-Typeset-MMv12F-Cov3.pdf.

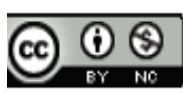

This work is licensed under a Creative Commons AttributionNon Commercial 4.0 International License. 